\title{
Complex homograft aortic reconstruction: New recipes from old ingredients
}

\author{
Neel R. Sodha, MD
}

\footnotetext{
From the Department of Surgery, Lifespan Thoracic Aortic Center; and the Division of Cardiac Surgery, Alpert Medical School, Brown University, Providence, RI.

Disclosures: Author has nothing to disclose with regard to commercial support.

Received for publication Dec 26, 2016; accepted for publication Jan 5, 2017.

Address for reprints: Neel R. Sodha, MD, Lifespan Thoracic Aortic Center, Division of Cardiac Surgery, Alpert Medical School, Brown University, 2 Dudley St, MOC 360, Providence, RI 02905 (E-mail: nsodha@ lifespan. org).

J Thorac Cardiovasc Surg 2017;153:e77-9

$0022-5223 / \$ 36.00$

Copyright (C) 2017 Published by Elsevier Inc. on behalf of The American Association for Thoracic Surgery http://dx.doi.org/10.1016/j.jtcvs.2017.01.027
}

In their report in this issue of the Journal, Philpott and Zemlin ${ }^{1}$ present a complex mycotic aortic arch pseudoaneurysm after thoracic endovascular aortic repair (TEVAR). To manage this highly lethal pathology, Philpott and Zemlin ${ }^{1}$ used 4 separate homograft segments to overcome the challenge of combined arch and descending thoracic aortic reconstruction in the setting of infection. By reversing the orientation of the proximal elements, a more natural aortic contour was achieved, and by combining separate homograft elements, enough graft was created for extensive aortic replacement. Philpott and Zemlin ${ }^{1}$ are to be congratulated for a successful outcome with a durable result at 2 years.

Management of endograft infection after TEVAR remains a formidable clinical challenge. Rates of graft infection after TEVAR range from $1.5 \%$ to $4.8 \%,{ }^{2,3}$ with mortalities that can exceed $70 \% .^{3,4}$

The spectrum of thoracic endograft infections ranges from early uncomplicated infections to advanced complex infection with aneurysm or fistula formation. The relatively low incidence and heterogeneity of this problem has led to a variety of management strategies reported in the literature, ranging from nonoperative management to complete resection and reconstruction, with guidance drawn from the management of standard prosthetic aortic graft infections and abdominal endograft infections.

When presented with an endograft infection after TEVAR, the initial question is whether to operate. The answer is almost invariably yes. Moulakakis and colleagues ${ }^{5}$ have recently performed a comprehensive literature review evaluating management of TEVAR infections. Summarizing the available literature, they found reports on 96 patients with TEVAR infections. Fifty-five of these patients were treated with a graft-preserving strategy, which included a variety of treatment approaches (medical and surgical). Although this group no doubt included patients who were considered to be too sick or frail to tolerate aggressive operative management, that the overall mortality

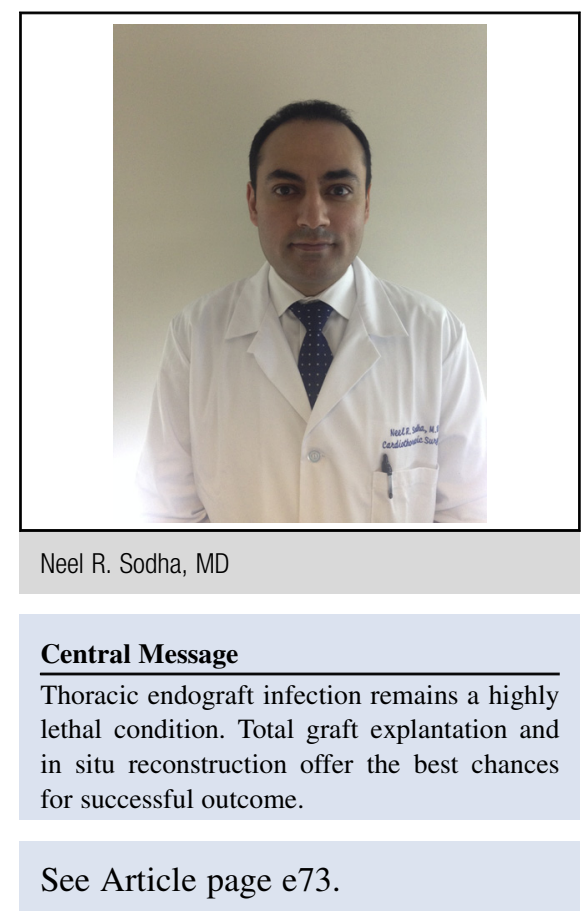

in this group was nearly $82 \%$ (compared with $46 \%$ in the graft explantation group) at a mean follow-up of 8.6 months highlights the poor outcomes with nonoperative and graft-preservation strategies.

Because of the poor outcomes reported with conservative therapy, most patients should be considered for aggressive surgical management once the diagnosis of endograft infection has been made or there is a high suspicion. Among these patients, early assessment for the ability to tolerate major open aortic reconstruction is essential. A subgroup, particularly those who have aortoenteral or aortobronchial fistulas with shock, or who have severe septic shock in the setting of a mycotic aneurysm, may benefit from TEVAR as a bridge to allow stabilization before a definitive open explantation. ${ }^{6}$

Once the decision has been made to proceed with definitive graft explantation, decisions must be made regarding in situ versus extra-anatomic reconstruction and conduit selection. Although it is theoretically appealing to avoid placement of a new conduit in an infected field, extra-anatomic reconstruction is often not feasible for thoracic aortic reconstruction because of anatomic limitations, particularly for infections involving the arch or proximal descending thoracic aorta. In addition, perioperative mortality may be significantly higher relative 
to in situ reconstruction $(67 \%$ vs $43 \%) .^{5}$ In practice, publications reviewing surgical management of thoracic endograft infections demonstrate that extra-anatomic bypass is used in fewer than $10 \%$ of graft explantation cases. $^{5,7}$

The area of greatest debate lies in conduit selection for aortic replacement. The 2 most widely utilized conduits are cryopreserved aortic homografts and antibiotic (rifampin)-soaked Dacron polyester fabric grafts. Advocates for homograft use cite resistance to early infection and decreased rates of later infection, as well as less need for aggressive débridement in complex anatomic fields. ${ }^{7,8}$ Potential limitations to the use of homografts are lack of widespread availability (especially in an emergency), limited sizing that may not provide an appropriate match for native vessels, the potential that enough homograft length may not be available for extended reconstructions, and the concern that not all surgeons will have technical familiarity with homograft use. Rifampin-soaked Dacron polyester fabric grafts may be associated with less resistance to infection than homografts, but their availability, range of sizes and lengths, and ease of use have made them common in aortic reconstruction in the setting of infection. Although there has been no head-to-head comparison of homografts versus antibiotic-soaked Dacron polyester fabric grafts in the management of thoracic endograft infection, a recent retrospective multi-institutional review by Smeds and colleagues ${ }^{7}$ reported on 26 TEVAR infections and 180 endovascular aortic repair infections. Five of the patients with TEVAR infections did not undergo surgery ( $80 \%$ mortality in this group), whereas of the 21 who had surgery for graft explantation, 16 of 21 had Dacron polyester fabric graft replacement of the aorta and 3 of 21 had homograft replacement. When discussing the results for the group as a whole (TEVAR and endovascular aortic repair), homografts demonstrated greater resistance to later infection than did antibiotic-soaked Dacron polyester fabric grafts, but because only 3 thoracic endografts were replaced with homografts, versus 16 with Dacron polyester fabric grafts, it is difficult to draw conclusions regarding superiority of bacterial resistance. Mean survival at 21 months was $29 \%$ in the TEVAR group undergoing graft explantation and reconstruction. Homografts probably have the most utility in complex infected fields where there is concern for ongoing contamination, such as aortoesophageal fistulas. If an antibiotic-soaked Dacron polyester fabric graft is used, most surgeons would recommend adjunct measures to protect the graft, such as wide, aggressive débridement, drainage, and the use of pedicled tissue flaps such as muscle or omentum. ${ }^{9}$

Additional conduit options to avoid the use of Dacron polyester fabric grafts for in situ aortic reconstruction include extracellular matrix derived from porcine small intestinal submucosa and xenopericardial grafts. The single case report of the use of extracellular matrix for aortic reconstruction described a suboptimal outcome and recommended additional laboratory investigation before further use. ${ }^{10}$ Xenopericardial roll grafts have been used by a number of groups with good results. Kubota and colleagues $^{11}$ and Czerny and colleagues ${ }^{12}$ have both reported excellent results in using bovine pericardial sheets to construct cylindric grafts, with durable results out to 3 years in 23 patients. Both groups cite the widespread availability of xenopericardium, ease of handling, ease of constructing large grafts, and theoretically decreased infectious risks as a result of glutaraldehyde preservation as reasons supporting xenopericardial roll grafts for use in reconstruction.

Although they did not advocate it as standard of care, Cernohorsky and colleagues ${ }^{13}$ demonstrated in a small, select series of patients that a graft-preserving strategy may have reasonable results. In their series of 12 patients with endograft infections without fistulas after TEVAR or endovascular aortic repair, 6 underwent surgery but only 4 of the 6 underwent graft explantation. The remaining 6 did not undergo surgical intervention. At 1-year followup, 5 of 6 patients from the surgical group were alive, and 4 of 6 from the nonsurgical group were alive, indicting that nonoperative management may have a small role in a highly select group of patients with early, uncomplicated infections.

In summary, graft infection after TEVAR remains a highly lethal condition regardless of management strategy. Nonoperative management and graft-preservation strategies are associated with very high mortalities and should be reserved only for patients too frail to tolerate any procedure. TEVAR may play a role as a bridge to open surgical explantation. The best outcomes are reported with total graft removal and reconstruction, generally with an in situ technique and soft tissue coverage, débridement, and drainage. The ideal replacement conduit has yet to be defined, but homografts, rifampin-soaked Dacron polyester fabric grafts, and xenopericardial grafts may all be reasonable options.

\section{References}

1. Philpott JM, Zemlin CW. Aortic reconstruction for an infected stent graft with a composite homograft. J Thorac Cardiovasc Surg. 2017;153:e73-5.

2. Lawrence PF. Conservative treatment of aortic graft infections. Semin Vasc Surg. 2011;24:199-204.

3. Chiesa R, Tshomba Y, Kahlberg A, Marone EM, Civilini E, Coppi G, et al. Management of thoracic endograft infection. J Cardiovasc Surg (Torino). 2010;51: 15-31.

4. LeMaire SA, Green SY, Kim JH, Sameri A, Parenti JL, Lin PH, et al. Thoracic or thoracoabdominal approaches to endovascular device removal and open repair. Ann Thor Surg. 2012;93:726-32; discussion 733.

5. Moulakakis KG, Mylonas SN, Antonopoulos CN, Kakisis JD, Sfyroeras GS, Mantas G, et al. Comparison of treatment strategies for thoracic endograft infection. J Vasc Surg. 2014;60:1061-71.

6. Szeto WY, Desai ND, Moeller P, Moser GW, Woo EY, Fairman RM, et al. Reintervention for endograft failures after thoracic endovascular repair. J Thorac Cardiovasc Surg. 2013;145(3 Suppl):S165-70. 
7. Smeds MR, Duncan AA, Harlander-Locke MP, Lawrence PF, Lyden S, Fatima J, et al. Treatment and outcomes of aortic endograft infection. J Vasc Surg. 2016; 63:332-40.

8. Vogt PR. Arterial allografts in treating aortic graft infections: something old, something new. Semin Vasc Surg. 2011;24:227-33.

9. Coselli JS, Spiliotopoulos K, Preventza O, de la Cruz KI, Amarasekara H, Green SY. Open aortic surgery after thoracic endovascular repair. Gen Thorac Cardiovasc Surg. 2016;64:441-9.

10. Abu Saleh WK, Al Jabbari O, Grande-Allen J, Ramchandani M. Extracellular matrix scaffold as a tubular graft for ascending aortic aneurysm repair. $J$ Card Surg. 2015;30:648-50.
11. Kubota H, Endo H, Noma M, Ishii H, Tsuchiya H, Yoshimoto A et al. Xenopericardial roll graft replacement for infectious pseudoaneurysms and graft infections of the aorta. $J$ Cardiothorac Surg. 2015;10:133.

12. Czerny M, von Allmen R, Opfermann P, Sodeck G, Dick F, Stellmes A, et al. Self-made pericardial tube graft: a new surgical concept for treatment of graft infections after thoracic and abdominal aortic procedures. Ann Thorac Surg. 2011;92:1657-62.

13. Cernohorsky P, Reijnen MM, Tielliu IFJ, van Sterkenburg SM, van den Dungen JJ, Zeebregts CJ. The relevance of aortic endograft prosthetic infections. J Vasc Surg. 2011;54:327-33. 